\title{
O perfil dos gestores de informação para a indústria capixaba
}

\author{
Eduardo Valadares da Silva \\ Bibliotecário da Prefeitura Municipal de Vitória (ES). \\ E-mail: edu_valadares@yahoo.com.br \\ Antonio Jorge Rodrigues Pereira da Silva \\ Coordenador do Sistema de Bibliotecas do Serviço Social da Indústria do Espírito Santo. \\ E-mail: jorgetown78@yahoo.com.br \\ Dulcinéa Sarmento Rosemberg \\ Mestre em educação e professora do Departamento de Ciências da \\ Informação, da Universidade Federal do Espírito Santo. \\ E-mail: dsrosemberg@globo.com \\ Isabel Cristina Louzada Carvalho \\ Mestre em educação e diretora da Gestão.Info Consultoria. \\ E-mail: atendimento@gestaoinfo.com.br
}

\section{Resumo}

0 estudo teve como objetivo mapear o perfil acadêmico e técnico-empresarial dos profissionais que atuam como gestores da informação para a indústria capixaba, buscando contextualizar o exercício profissional do bibliotecário. Realizou-se pesquisa exploratório-descritiva, com aplicação de formulário com questões abertas e fechadas. Os resultados permitem inferir que a maioria dos profissionais desconhece as etapas do processo de gestão da informação. Constatou-se reduzida presença de bibliotecários atuando no setor de informação dessas indústrias, mas que 0 setor está aberto a profissionais que busquem a composição de um perfil inovador diante das demandas de um mercado dinâmico, e que 0 bibliotecário pode vir a ser importante ator na construção desse novo cenário.

\section{Palavras-chave}

Informação para negócios. Informação para a indústria. Análise de perfil profissional.

\section{The profile of information managers for industry in Espírito Santo}

\section{Abstract}

The objective of this article is to map the academic profile of entrepreneurial professionals who work as information managers for industry in Espírito Santo State trying to contextualize the librarian's work. Thus, an exploratory and descriptive research, based on a questionnaire with broad and narrow questions was done. The results suggest that most of the information workers do not know the procedural levels of information management. The results also suggest that there are a small number of librarians working at industries in the state, but that industry is open to workers aiming to be part of an innovative profile before the newest demanding of a dynamic market. Librarians may become a very important agent for constructing this new scenario.

\section{Keywords}

Information management. Information industry. Professional profile analysis.

\section{INTRODUÇÃO}

O Espírito Santo é um dos estados brasileiros que vem mantendo lugar de destaque no cenário nacional, devido à média crescente de sua economia. Entre os anos de 2001 e 2006, o estado acumulou crescimento industrial de $27,1 \%$, registrado como acima da média brasileira que, para o mesmo período, foi de 16,4\% (INSTITUTO EUVALDO LODI, 2007). Um conjunto de fatores estruturais importantes tem dado corpo a esse crescimento: a localização estratégica na região Sudeste; a logística privilegiada com vias de escoamento da produção por rodovias, ferrovias e/ou portos; os produtos altamente fortalecidos no mercado internacional, tais como aço, minerais, celulose, produtos químicos e outros.

Os recursos naturais do Espírito Santo, somados a uma indústria forte em praticamente todos os segmentos, com investimentos crescentes em tecnologia de ponta e métodos modernos de gestão e planejamento estratégico, fazem da indústria o setor com maiores investimentos no estado, superada apenas pela área de energia, que vem crescendo na mesma proporção, devido, justamente, a esse alicerce demandado pela indústria ao longo de seu desenvolvimento.

De acordo com estudos do Instituto de Apoio à Pesquisa e ao Desenvolvimento Jones dos Santos Neves (2005), até o ano de 2010, estão previstos investimentos na ordem de $R \$ 14,85$ bilhões na indústria capixaba, o que representa 33,65\% do total de investimentos no estado, além da criação de 40.684 empregos nesse setor. Um dos fatores que se observa diante desse quadro otimista é necessidade urgente e crescente das indústrias em adquirir, organizar e disseminar informações e conhecimento, isto é, investir na estruturação dos seus sistemas de gestão de informação, conhecimento e inovação.

Especialistas diretamente ligados à condução de projetos de desenvolvimento do setor industrial no estado são incisivos em confirmar o ambiente favorável à continuação desse crescimento, como menciona o presidente da Federação das Indústrias do Espírito Santo (Findes), Lucas Izoton, ao afirmar que

[...] a indústria capixaba vem se desenvolvendo, a cada ano, de maneira muito intensa, principalmente as indústrias voltadas para as grandes plantas industriais, que 
têm commodities e têm, no mercado externo, sua maior clientela (FINDES avalia..., 2005, p. 2).

Ainda conforme essa instituição, a perspectiva é que a indústria gere 40.684 vagas de trabalho no Espírito Santo, até 2010, ficando evidente a sua importância econômica e social no desenvolvimento capixaba, apesar de ser superada em valores de investimentos pelo setor energético, mas não em número de empregos criados.

Foram essas inquietações que motivaram a realização do presente estudo, que tem como objetivo mapear o perfil acadêmico e técnico-empresarial dos profissionais que atuam como gestores da informação para a indústria capixaba, buscando contextualizar o exercício profissional do bibliotecário.

\section{CAMINHOS METODOLÓGICOS}

Segundo o Instituto Euvaldo Lodi (IEL-ES) e o Instituto de Desenvolvimento Industrial do Espírito Santo (Ideies), que publicaram o Guia de Negócios do Espírito Santo, em 2002, o estado possuía parque industrial de 6.388 empresas. No entanto, devido ao considerável crescimento do setor nos últimos anos, a expectativa é que o estado venha a reunir número cada vez maior de indústrias, em diferenciados setores. Os dados atualizados pelo IEL-ES, até o mês de março de 2007, ratificam essa expectativa, uma vez que o instituto afirma, por meio de dados prévios, que o estado conta com total de 7.104 indústrias, destacando-se as de produtos de minerais não-metálicos, produtos alimentícios e de bebidas, comércio e reparação de veículos automotores e motocicletas, artigos do vestuário e acessórios, construção, extração de minerais não-metálicos, móveis, produtos de metal (exclusive máquinas e equipamentos), informática e conexas, e máquinas e equipamentos, como os setores da indústria que concentram número mais expressivo de empresas atuando no mercado (INSTITUTO EUVALDO LODI, 2007).

Em suma, nesse espaço-tempo, executou-se uma pesquisa exploratório-descritiva do tipo levantamento que, em um universo de 1.597 empresas, tomou como parâmetro, para definição da população-alvo, as 56 maiores indústrias capixabas, de acordo com o ranking publicado pelo IEL-ES, na revista 150 Maiores Empresas no Espírito Santo, referente ao ano de 2003, que considera para a classificação os balanços com Renda Operacional Bruta (ROB) superior a R \$2 milhões, e para a composição dos rankings setoriais, a $\mathrm{ROB}$ superior a R\$1 milhão (PARTICIPAÇÃO..., 2004).

Desse quantitativo, usando como critério a existência de um profissional que se enquadrasse, segundo a visão da empresa, como o responsável pela gestão da informação, foi definida amostra de $25 \%$, perfazendo total de 14 indústrias, pertencentes a variados ramos de atividades: alimentos, agrícola, construção civil, energia, caixas d'água e materiais plásticos, mármore e granito, metalúrgica, mineração, logística e transporte, química, siderurgia, tubos e conexões.

Nas 56 indústrias que compõem o ranking mencionado, para escolher os sujeitos que participariam da pesquisa, utilizou-se o mailing fornecido pelo IEL, trazendo dados completos das empresas, o que facilitou o contato direto com o seu principal executivo, com a assessoria ou a secretária executiva, que indicou o profissional responsável pela gestão da informação. Essa tarefa foi realizada com relativa dificuldade, porque os funcionários pareciam não reconhecer de imediato o responsável pela gestão da informação no âmbito da indústria, mesmo que questões diretas tenham sido dirigidas, tais como: quem é o profissional responsável pela gestão de informação na empresa? Há algum setor responsável por prover a indústria de informações estratégicas ou competitivas? A empresa mantém uma unidade de informação especializada, como biblioteca, centro de documentação ou similares?

Desse modo, a escolha da amostra se deu pelo critério de tipicidade ou intencionalidade que, segundo Gil (1999, p. 104),

[...] constitui um tipo de amostragem não probabilística e consiste em selecionar um subgrupo da população que, com base nas informações disponíveis, passa a ser considerado representativo de toda a população.

Mesmo assim, no decorrer da etapa de coleta de dados, a amostra inicial de $25 \%$ foi reduzida para $21,42 \%$, representando 12 indústrias, devido a fatores como impossibilidade de atendimento por parte dos profissionais, que alegaram falta de tempo; período de férias e licenças médicas; normas internas das empresas que impedem a participação de seus colaboradores em pesquisa de nível acadêmico.

Para alcançar os objetivos propostos, adotou-se, como instrumento de coleta de dados, o formulário com questões abertas $^{1}$ e fechadas, por ser uma técnica que permite contato direto com a população-alvo, o que facilita a percepção de reações e comentários adicionais que vão além do preenchimento das questões propostas por um questionário que, muitas vezes, pode vir a ser respondido em circunstâncias indesejáveis, ou da entrevista que requer um nível de complexidade maior para sua operacionalização (GIL, 1996).

\section{PERFIL ACADÊMICO DOS GESTORES}

Dos 12 profissionais pesquisados, oito pertencem ao gênero masculino, das áreas de conhecimento como engenharia

1 As falas reproduzidas neste texto estão transcritas em formato itálico para serem diferenciadas das citações dos autores consultados, e entre aspas para garantir a individualidade dos sujeitos que colaboraram com a pesquisa. 
(três profissionais), ciências contábeis (dois profissionais) e agronomia, ciência da computação e direito, com um profissional em cada área. Os outros quatro referem-se ao gênero feminino, pertencentes a área de biblioteconomia. Esses dados revelam a predominância de homens atuando no setor de informação para a indústria, o que não é de se estranhar, visto que o mercado de trabalho como um todo é majoritariamente ocupado pelo gênero masculino e, ao mesmo tempo, corroboram a feminização da profissão do bibliotecário.

Nota-se que há freqüência maior de bibliotecários atuando, ao se analisarem os resultados isoladamente (quatro indivíduos); todavia, a presença pulverizada de profissionais oriundos de outros cursos é mais marcante (oito indivíduos), ou seja, o dobro de bibliotecários, representando supremacia desses profissionais da área de ciência da informação.

Em suma, os resultados obtidos pelas pesquisas realizadas, desde os anos 90, em várias partes do país, alertam que a participação de bibliotecários nos setores de informação para a indústria, para negócios e nas áreas tecnológicas é bastante tímida, se comparados com os de outras áreas, como administração (38,2\%), economia (21,4\%), ciências humanas $(16,1 \%)$ e contabilidade $(11,4 \%)$, que conseguem inserir seus profissionais nos segmentos brasileiros apontados. Exemplo confirmando essa afirmativa foi o estudo realizado por Montalli (1997), também no segmento industrial brasileiro, tendo como ambiente a Rede de Núcleos de Informação Tecnológica do Padct, o Sistema de Informação do Sebrae e o Sistema de Informação da $\mathrm{CNI}$, quando constatou que, em um universo de 272 respondentes, somente $8 \%$ deles possuíam formação em biblioteconomia.

Tarapanoff (2001) e Tarapanoff, Araújo Júnior e Cormier (2000) são outros pesquisadores que se preocupam com a baixa inserção do bibliotecário no setor de informação, em nível nacional, reafirmando que as pesquisas sobre mercado de trabalho apontam um cenário em que esse profissional ainda ocupa o mercado tradicional, voltado para atuação em bibliotecas públicas e especializadas ou centros de documentação, cujo empregador ainda é o setor público.

No Espírito Santo, apenas 20,6\% das empresas públicas e privadas empregam bibliotecários. Nesse percentual, as denominações dos setores em que eles atuam (centro de informação e documentação, biblioteca, arquivo central, centro de informações técnicas e pesquisa) e a maioria dos cargos a eles atribuídos (bibliotecário, analista de documentação e arquivo, auxiliar administrativo) remetem à interpretação de um fazer tecnicista e pouco ousado (BIANCARDI et al., 2003).

Por sua vez, Damásio e Longo (2002, p. 19), em investigação no município de Maringá (PR), não localizaram "[...] nenhum profissional bibliotecário, o que vem caracterizar uma provável indefinição de suas funções neste segmento, apesar de as indústrias pesquisadas serem de grande porte [...]", o que parece validar a hipótese levantada pelos autores. A visão do empresariado capixaba sobre as funções que podem ser desempenhadas por bibliotecários ainda é de cunho predominantemente técnico (serviços de catalogação, classificação de suporte de informação, atendimento aos funcionários, etc.), o que pode gerar a indefinição sobre outras funções relacionadas com a gestão da informação, como explicam Biancardi et al. (2003), a partir de estudo sobre o cenário do mercado de trabalho do bibliotecário, na perspectiva desses empresários.

Damásio e Longo (2002, p. 19), parafraseando Schwarzwalder (1999), no que diz respeito ao baixo grau de empregabilidade dos bibliotecários na indústria brasileira, informam que

[...] o principal motivo é a cultura organizacional nas empresas, que tendem a utilizar outros profissionais não bibliotecários para gerenciar informação, sendo uma desvantagem bastante óbvia a este profissional. Desta forma, a não-utilização de bibliotecários neste segmento pode se dever a um fator cultural.

Em síntese, apesar da afirmação de

[...] que o bibliotecário está apto a candidatar-se a cargos além do tradicional, podendo sim pleitear cargos que tenham em sua descrição e exigências, experiências relacionadas à gestão da informação" (DAMÁSIO; LONGO 2002, p. 21)

e da anunciada abertura do mercado informacional ao bacharel em biblioteconomia, até o presente momento, ainda não houve a concretização dessa proposta.

Não há pretensão de se defender o monopólio da atuação de bibliotecários como responsáveis pelo gerenciamento dos recursos informacionais das empresas, mas sim de minimizar a desvantagem que ainda é óbvia, se comparada com outras profissões que têm preferência pelo desenvolvimento dessa atividade. Tal afirmação vai ao encontro do que preceituam Arruda, Marteleto e Souza (2000, p. 14), ao concluí que,

[...] sob uma nova materialidade, a informação, no novo modelo econômico, é percebida como um valor, dada a possibilidade de vir a se transformar em conhecimento e em inovação tecnológica. Esta nova dimensão da informação, aliada ao desenvolvimento tecnológico, desvincula a informação de espaços restritos e de monopólios profissionais.

Para Biancardi et al. (2003), o empresário capixaba parece que ainda não se deu conta das novas atribuições e valores incorporados à biblioteconomia moderna, tampouco os 
bibliotecários se tocaram para as oportunidades que têm surgido. Na contramão do que fazem os bibliotecários, profissionais de áreas como administração e comunicação, por exemplo, têm assumido uma atuação mais abrangente em novos postos de trabalho no mercado informacional, incorporando uma ótica globalizada sobre as mudanças e inovações tecnológicas e humanísticas. Com relação aos perfis profissionais emergentes, autores, como Miranda (2004, p. 118), informam que estes são os

[...] gestores de informação, os trabalhadores, engenheiros e gestores do conhecimento, e os especialistas em gestão do conhecimento, em conteúdos informacionais e em uso de ferramentas inteligentes. Não há um perfil único para o profissional da informação ou do conhecimento.

Uma explicação para o fato de os bibliotecários continuarem a atuar apenas em áreas de informação tradicionais pode ser fruto da falta de sua interatividade com os demais profissionais, o que, de certa forma, faz com que suas funções fiquem cada vez mais marginalizadas, ocasionando menor participação no mundo do trabalho, em segmentos como a indústria, como afirmam McGee e Prusak (1994).

Destarte, a baixa empregabilidade desses profissionais nesse setor requer uma atenção especial à formação especializada desde a formação inicial até a continuada. Os resultados deste estudo confirmam que dez gestores de informação para a indústria possuem curso de especialização e apenas dois realizaram mestrado (educação e contabilidade e controladoria). Dos quatro bibliotecários que atuam no segmento, três possuem especialização: dois realizaram cursos em áreas da ciência da informação, como documentação e informação e arquivo, e o outro preferiu se especializar em administração de empresas e em educação. Quanto aos demais com formação em outras áreas, percebe-se que também há freqüência considerável de participação em cursos de especialização cujas áreas escolhidas têm ligação direta com o negócio da empresa em que atuam (gerenciamento de projetos, gestão empresarial, auditoria e análise de balanços, engenharia de manutenção, segurança do trabalho, engenharia de produção).

O número de profissionais com mestrado e a inexistência de doutores e pós-doutores permitem concordar com Montalli (1997, p. 292), que já identificara situação semelhante. Na oportunidade, a pesquisadora evidenciou que se apresenta

[...] insignificante o resultado no que se refere aos cursos de mestrado. Questiona-se, então, como esses sistemas de informação tratam a questão das lideranças na área. Que papel eles desempenham, dentro e fora de seus sistemas? Que visões macro possuem das questões referentes aos sistemas a que pertencem? Que soluções aos problemas da área de informação para empresa/ indústria no país são capazes de sugerir e/ou implementar? Doutores também fazem-se necessários, nessa área, para ocupar os cargos de maior responsabilidade e destaque, para contribuir com o encaminhamento das questões da área [...].

No Espírito Santo, para fomentar a participação e aumentar o status profissional dos bibliotecários nos segmentos industriais capixabas, uma das possibilidades pode ser o investimento em modalidades mais avançadas de pós-graduação, como mestrado e doutorado em áreas que exijam inovação e, em especial, naquelas relacionadas com os principais arranjos produtivos locais, tais como confecções, móveis, mármore/ granito e petróleo/gás.

Diante do quadro em tela, certas de que o atendimento aos pólos tecnológicos implica formação especializada em gestão da informação para ciência e tecnologia e para negócios, Rosemberg, Correa e Fraga (2007), ao finalizarem uma proposta de reformulação curricular para o curso de biblioteconomia da Universidade Federal do Espírito Santo, concretizada na perspectiva da pesquisa científica, recomendaram a formação dos egressos a partir de duas ênfases, a saber: uma em informação social e outra em informação para a ciência e tecnologia. Propõe-se, portanto, que, para além da especialização requerida, já na graduação, busquese potencializar a intelectualidade dos bibliotecários, o que poderá se reverter em atividades mais qualitativas, de modo que venham a ser absorvidos pelo segmento empresarial na dimensão preconizada pelos empresários capixabas.

Para esses empresários, os colaboradores responsáveis pelo setor de informação devem tornar-se consultores internos de informação, conhecer os produtos e serviços oferecidos pela empresa, ser especialistas dedicados ao tratamento da informação, conhecer as tecnologias de informação e ser atuantes e competentes na satisfação das demandas de informação do diversificado grupo de profissionais da empresa (BIANCARDI et al., 2003).

Com relação ao domínio de idiomas estrangeiros que sempre figura como pré-requisito essencial ao perfil profissional, independentemente da área do conhecimento, neste estudo ficou comprovado que o inglês concentra o maior nível, uma vez que seis têm dele domínio básico, cinco, nível intermediário, e apenas um manifestou possuir domínio avançado da língua inglesa. Quanto ao espanhol, sete informaram que dominam o idioma. Em contrapartida, apenas dois têm domínio básico da língua francesa.

Considerando que o inglês se configura como língua tradicionalmente aceita como universal e que a maioria das indústrias pesquisadas atende ao mercado externo, é natural que esse idioma seja predominante entre os gestores de informação para a indústria, o que não impede a busca por competências em outros idiomas. 
Além disso, para que as organizações possam tomar decisões de maneira ágil e qualitativa, é muito importante que haja eficiente sistemática de comunicação que possibilite rápida circulação das informações e conhecimentos necessários a esse processo. Para tanto, é imprescindível que esteja à disposição e sob controle de seus colaboradores um suporte tecnológico adequado. (ANGELONI, 2003). Nesse sentido, quanto ao nível de conhecimento em informática dos agentes responsáveis pelo gerenciamento dos recursos informacionais das empresas, apurou-se que, como usuários de informática, ou seja, na operação de softwares, como pacote Office, bancos de dados diversos e outros, específicos de cada empresa, a grande maioria (sete pesquisados) possui domínio avançado, seguido por três com nível intermediário e dois com nível básico, não havendo declarações total falta de conhecimento.

No que diz respeito à categoria de analista (construção de softwares, ferramentas de tecnologia de informação, manutenção etc.), apenas um respondente assegurou ter domínio avançado, enquanto três afirmaram ter domínio básico e a maioria (sete respondentes) não possui nenhum domínio nesse sentido. $O$ fato de identificar-se uma pessoa com domínio avançado nessa categoria explica-se pela especificidade de seu cargo como coordenador de tecnologia de informação e formação em ciência da computação. Portanto, esse nível de conhecimento não se configura como parâmetro necessário ao delineamento do perfil ideal.

Entende-se que o pequeno ou quase inexistente domínio em nível avançado, como analistas, não compromete a qualidade dos serviços prestados, uma vez que a maioria confirmou possuir avançado conhecimento como usuário. Nessa discussão, Silva, S. L. da (2002, p. 150) afirma:

A tecnologia de informação] pode ajudar, mas o foco principal deve ser as mudanças necessárias nos processos da empresa (que precisam mudar para incorporar atividades de coleta e utilização do conhecimento), os papéis e responsabilidades na organização (por exemplo, quem capta e quem conserva as informações) e os incentivos (por exemplo, o que fazer para que as pessoas contribuam com seus conhecimentos).

Essa constatação não implica que a tecnologia de informação se configure como item pouco importante, pelo contrário, é notória sua importância ao alcance da melhoria de custos de produção, qualidade de produtos de serviços, acompanhamento das tendências de mercado e outras. Para isso, entretanto, deve ser concebida como um dos instrumentos para o alcance dessas vantagens competitivas, e não como um fim em si mesma.

Quanto a conhecimentos adicionais necessários ao gestor de informação para a indústria, foi indagado se julgam importante ou não obtê-los. Em caso afirmativo, solicitou-se que os indicassem e justificassem a importância de adquiri-los ou não. Nessa direção, dez respondentes julgaram importante investir na aquisição de outros conhecimentos. Entre os bibliotecários, um demonstrou maior atenção à parte técnica do fazer biblioteconômico, tendo interesse em "cursos sobre conservação e outros relacionados às áreas de atuação da unidade de informação". Outros três expuseram ter interesse não somente em áreas técnicas da profissão, mas também em outras, como

"O funcionamento da empresa em que atua. Conhecimento das normas internas, procedimento, processos e documentos (burocracia) da empresa. Isso pode ser adquirido através de softwares de gerência da informação".

"Hoje, além de ser bibliotecária, devemos ter conhecimento na área de gestão do conhecimento, de informática, sobre trabalho em equipe, qualidade total e normalização. São todos conhecimentos que ajudam no desempenho da na função, mesmo não tendo a função de chefe ou gerente. Por coordenar o Centro de Informações Técnicas, preciso conhecer parte da administração para imprimir dinâmica à equipe que coordeno".

"Atualização dentro da própria área de atuação, como: gestão de pessoas (relacionamento humano com os colaboradores, atendimento a clientes, relacionamento interpessoal e legislação), legislação de gestão de contratos (uma vez que a terceirização é fato real nas empresas), tecnologia de informação (o mundo atual não pode ser vivido sem ela), gestão ambiental e de processo".

Percebeu-se que os demais profissionais foram enfáticos em assegurar que primeiramente se deve conhecer o ambiente organizacional em que atuam e respeitar suas peculiaridades, normas internas, burocracias e outras. Nota-se que há preocupação, por parte dos profissionais, em conhecer a fundo a empresa, para que suas ações estejam embasadas e em consonância com os objetivos da instituição, como se pode observar nas falas a seguir:

"Na área de tecnologia de informação, o universo é muito grande. $\mathrm{Na}$ realidade, você tem que determinar em que área vai atuar (segurança, sistemas, redes, telecomunicações) e, em cima disso, tem uma infinidade de cursos extracurriculares muito bons e importantes para fazer".

"Conhecimento do mercado em que a empresa atua e de seus clientes".

"Atualização constante na parte técnica e gerencial, além de conhecer 'o todo' dentro da empresa".

"Cursos e palestras específicas da área de interesse". 
"Buscar conhecimentos adicionais nas áreas de engenharia elétrica e civil".

"Cursos de atualização que tenham como objetivo oferecer qualificações na área de engenharia civil, particularmente no que diz respeito à licitação de obras e oportunidades no negócio imobiliário".

Esses aspectos retratam a preocupação com a especialização, em suas respectivas áreas de abrangência, com o intuito de dar maior qualificação às suas atividades, diante da amplitude dos segmentos em que atuam. Por fim, mas não em segundo plano, citam os conhecimentos de aperfeiçoamento das atividades interpessoais, como motivação, trabalho em equipe etc.

Apenas dois entrevistados, que não possuem formação em biblioteconomia, julgaram não ser importante investir na obtenção de novos conhecimentos, justificando que os recursos informacionais da empresa e a formação que possuem já atendem às necessidades, afirmando que já dispõem dos recursos necessários para a gestão da empresa e para a busca de informações necessárias ao desenvolvimento do negócio.

Quando interrogados sobre treinamentos, dez declararam haver participado de ações nesse sentido. Constata-se, a partir da análise desses dados, que a maioria participou de mais de um curso, nos seis meses anteriores à pesquisa, o que demonstra a importância dada à complementação profissional. Analisando os depoimentos dos entrevistados sobre esse assunto, verificaramse duas ênfases em treinamentos, uma voltada para as áreas que estão no foco de atuação das empresas, seguindo a tendência de especialização, tanto na área de informação quanto em outras que dizem respeito a manejo de matérias-primas, gestão da qualidade, processos de licitação, aprimoramento de domínio de informática e gerenciamento de softwares e outros que se convertem em resultados direto às instituições. A outra linha é mais direcionada ao enriquecimento e aprimoramento das relações interpessoais e de trabalho em equipe, seguindo a tendência das empresas em investir e priorizar a valorização humanística de seus colaboradores.

\section{PERFIL TÉCNICO-EMPRESARIAL DOS GESTORES DA INFORMAÇÃO}

De acordo com o que informaram os profissionais, há grande diversidade de uso de termos para designar os seus cargos, por exemplo, no caso dos bibliotecários são descritos como bibliotecário ou assistente de documentação. Os demais profissionais informam as seguintes designações: analista administrativo, chefe de departamento, coordenador administrativo, coordenador de controladoria, coordenador de tecnologia de informação, country manager, gerente de exportação e marketing, gerente operacional e supervisor técnico. Concluiu-se, a partir disso, que não há uma ligação explícita, em termos de nomenclatura, com as designações próprias da área de informação, ressalvando-se o coordenador de tecnologia de informação. Entretanto, fica evidente que os profissionais estão sujeitos aos termos adotados pela política de cargos e salários da instituição em que atuam.

Pode-se dizer que são diversas as possibilidades de o bibliotecário se candidatar a cargos estratégicos nas empresas, desde que atenda aos requisitos estabelecidos pelo mercado de trabalho e que o setor sob sua gerência tenha abrangência e fluxo de comunicação eficientes com os demais setores da empresa. Essa afirmação é ratificada por Damásio e Longo (2002, p. 21), quando asseguram

[...] que o bibliotecário está apto a candidatar-se a cargos além do tradicional, podendo sim pleitear cargos que tenham, em sua descrição e exigências, experiências relacionadas à gestão da informação.

Ainda sobre essa diversidade de cargos nas empresas, Marchiori (2002 p. 74) observa que

[...] aos profissionais da informação 'tradicionais' (arquivistas, bibliotecários, museólogos, profissionais dos meios de comunicação de massa, informáticos), agregaramse outros, ditos 'emergentes', cujas denominações no mercado de trabalho indicam forte interação de habilidades e conhecimentos técnicos e gerenciais disponíveis na área de profissionais de informação e de outras áreas, tais como educação, marketing, história, administração, economia (web designers, engenheiros de conteúdo, arquitetos de informação, entre outros).

Para vislumbrar futuros cenários, optou-se também por verificar as principais funções desempenhadas pelos gestores da informação para indústria. Quanto às principais funções desenvolvidas pelos profissionais com formação em biblioteconomia, essas podem ser evidenciadas a partir das falas a seguir:

\section{"Coordenar o Centro de Documentação e Memória [...]".}

"Gerenciar a parte técnica do Centro de Informações Técnicas; coordenar o Projeto da Memória, visando a resgatar a memória da empresa para fins de publicação de um livro; colaborar com o Programa de Educação Ambiental; desenvolver projetos de ação cultural ao recebermos escolas carentes, com o objetivo de mostrarmos a importância do hábito de leitura; implantar bibliotecas setoriais; além de desenvolver programa de consultoria junto aos funcionários que participam de eventos fora da empresa, buscando reunir as informações absorvidas [por eles durante os encontros], visando a colocá-las à disposição daqueles funcionários que não participaram do evento".

"Gerenciar o Centro de Documentação Temporária do Complexo de Tecnologia de Informação; prestar consultoria 
aos arquivos ativos das gerências de suprimentos, de $\mathrm{RH}$, de ferrovia e às empresas coligadas".

"Gerenciar o Centro Documentações Técnicas, o que engloba seus recursos humanos e materiais; efetuar empréstimos, prestar atendimento [aos usuários], realizar catalogação e aquisições que, apesar de serem tarefas mais simples, não podem ser esquecidas. Além de prestar apoio informacional a todas as gerências".

A expectativa do bibliotecário em atuar no contexto mais amplo da gestão da informação não significa que deva haver rompimento com o aspecto técnico da profissão, uma vez que esse é um diferencial profissionais que possuem formação em outras áreas de conhecimento. Ou seja, as técnicas de tratamento, recuperação e disseminação da informação tornam-se instrumentos estratégicos da sua atuação, mas sempre primando pela complementação profissional que propicie prática profissional inovadora e empreendedora, requisitada hoje pelo mundo do trabalho, em especial, no setor de gestão da informação.

Biancardi et al. (2003) também identificaram que 70,6\% dos empresários capixabas pesquisados atribuem aos bibliotecários cargos e funções caracteristicamente técnicos (responsabilidade de execução de serviços, como catalogação, classificação de suporte de informação, atendimento aos funcionários etc.). Quanto às características administrativas mais abrangentes (direção, chefia, coordenação, supervisão etc.), apenas 23,5\% julgam possível que o bibliotecário exerça funções desse nível. Os 5,9\% restantes atribuem responsabilidades diversas (auxílio administrativo, digitação etc.) nada ligadas ao moderno fazer biblioteconômico. Como destacam as autoras, isso se deve ao desconhecimento dos empresários sobre a profissão do bibliotecário, na perspectiva disseminada pela literatura técnico-científica da área.

Neste estudo, visualizou-se que os oito profissionais com formação em outras áreas de conhecimento são responsáveis pela gestão da informação nas indústrias pesquisadas, encontrandose em setores estratégicos. Além disso, seus cargos possuem autonomia para tomada de decisão, que envolve desde o planejamento estratégico até a área de produção.

Nesse cenário, portanto, fica evidente que é preciso, a partir das exigências de uma sociedade de caráter mercantil, que o bibliotecário passe a assumir uma postura mais interativa e proativa, sendo necessário que detenha qualificações formais e capacidades tácitas colocadas a serviço da produção e da obtenção de resultados profissionais (BRAGA, 2002). Com a assimilação dessas exigências, talvez lhe seja possível uma atuação na perspectiva do profissional da informação, como evidenciado por Ferreira (2003, p. 44), para quem pode ser:

[...] o analista de negócios, que, buscando soluções de tecnologia capazes de alavancar a competitividade dos processos empresariais, traz informações do mundo exterior sobre melhores práticas, tecnologias emergentes,

ou aquele

[...] responsável pelo acervo de documentação da empresa, abrangendo textos, artigos, livros, periódicos, manuais, plantas, especificações técnicas, estruturando e mantendo a memória organizacional. Ou até mesmo o profissional de marketing preocupado com a pesquisa, captação, seleção, qualificação, análise e comunicação das informações sobre o mercado, o desempenho da empresa e da concorrência. E também não se pode esquecer o profissional de recursos humanos, voltado para a formação e sustentação de comunidades de práticas dentro da empresa, cujo objetivo é o compartilhamento do conhecimento (TEIXEIRA FILHO, 1998, p. 2).

Rezende (2002, p. 75) afirma que as empresas vêm agregando à sua estrutura profissionais com perfis ligados uso e interpretação da informação que são denominados agentes do conhecimento criativos, intérpretes e intermediários. Conforme a autora, os agentes criativos são aqueles

[...] que utilizam informação na solução de problemas, ou como insumo gerador de idéias que irão fundamentar novas tecnologias e conceitos que, por sua vez, irão proporcionar vantagem competitiva.

$\mathrm{Na}$ presente pesquisa, constata-se que há profissionais que se enquadram na categoria de agente, uma vez que a eles são demandadas informações sobre extensão e transferência de tecnologias, técnicas para normatização de processos, parcerias e tendências de evolução do mercado.

Os agentes intérpretes, que analisam o contexto de atuação da organização utilizando a informação como ferramenta de prospecção e identificação de novos negócios, mercados e tecnologias, tornam-se especialistas em análise e planejamento econômico, comercial ou tecnológico, com a missão de identificar ameaças e oportunidades para antecipar mudanças de cenário. No setor estudado, fazem-se presentes esses agentes, visto que são responsáveis pelas informações sobre conjunturas econômicas; empresas concorrentes; fornecedores de máquinas, equipamentos, matéria-prima e insumos indicadores socioeconômicos; mercados de atuação; oportunidades de negócio.

Para Rezende (2002, p. 76), os agentes intermediários, por sua vez, são

[...] os especialistas em intermediar o acesso à informação, cujo processo se inicia com a identificação e interpretação das demandas de informação do negócio, seguida da identificação das fontes de informação, seleção e pesquisa propriamente dita, da organização que torna as informações 
acessíveis e, por fim, da sua divulgação para os agentes de conhecimento existentes na empresa.

Acredita-se que, como nas demais indústrias de grande porte, nas indústrias capixabas, considerando a tipologia de informação demandada (controle de qualidade, oportunidades de negócios, conjunturas socioeconômicas, informação sobre extensão e transferência de tecnologia, formação de recursos humanos, entre outros tipos de informação) podem ser localizados os agentes intermediários, como preconizado por Rezende (2002).

Nesse sentido, existe uma tendência que divulga a importância das competências interpessoais, conceituais e da competência técnica que devem compor o perfil do profissional, porque são guias de uma atuação mais adequada do profissional envolvido com o processo de gestão da informação. Seguindo essa tendência, Zarifian (2003, p. 37) enuncia competência como

[...] uma nova forma de qualificação ainda emergente. É uma maneira de qualificar. [...] não se deve fazer nenhuma distinção conceitual entre competência e qualificação, a não ser para dizer que o modelo da competência especifica, hoje, de maneira nova, a construção da qualificação.

Complementando essa discussão, Nordhaug citado por Miranda (2004, p. 116) explicita competências interpessoais como "[...] os comportamentos humanos e os processos interpessoais, a empatia e a sensibilidade social, a habilidade de comunicação e a capacidade de cooperação [...]" e as competências conceituais como "[...] a capacidade analítica, a criatividade, a eficiência em resolver problemas e a habilidade de reconhecer oportunidades ou problemas potenciais".

No que se refere às competências técnicas, Santos e Rosa (2005, p. 26) assim as explicitam:

[...] aquelas incorporadas durante a formação acadêmica e aprimoradas depois durante o percurso profissional, complementam e proporcionam uma atuação mais abrangente e eficaz, tanto no âmbito profissional, quanto no social.

A partir da definição das competências necessárias ao profissional de gestão de informação, diversas características foram apresentadas e analisadas por grupos de níveis de importância, na seqüência de imprescindíveis, importantes e desnecessárias, segundo a percepção dos sujeitos, visando a aferir, na prática, características necessárias para compor o perfil esperado. Entre as citadas como imprescindíveis ao profissional, foram apontadas a eficiência e a capacidade de trabalhar em grupo, por 11 entrevistados.

A eficiência é indicada como uma característica imprescindível a qualquer profissional, pois, como argumenta um dos respondentes: "É um pouco relativo. Em qualquer profissão temos que ter eficiência. Mesmo não sendo 100\%, temos que buscar o máximo de eficiência”.

O trabalho em grupo também é interpretado como elemento de destaque nesse escopo profissional:

"Porque o trabalho na nossa área é todo interligado. E, assim, não cabe você trabalhar de forma individual, pois uma informação vai cruzar com outra lá na frente".

"Dividir responsabilidades é importante para obtenção de resultados".

"É necessário que todos ajam em conjunto para alcançar resultados. No nosso caso, isso é demonstrado no trabalho de envolvimento com o planejamento estratégico".

Adequadamente, já em 1997, Montalli defendia, de maneira enfática, a atuação desse profissional no setor industrial, não como um membro a mais na equipe, mas como líder e agente de integração. Além disso, com a adoção dessa forma de trabalho, as responsabilidades são divididas, propiciando multiplicidade de visões.

Através do trabalho em equipe, pode-se obter o maior número de informações e perspectivas de análise distintas, sendo validada a proposta mais interessante no confronto argumentativo no grupo de trabalho (GUTIERREZ, 1999).

Outra característica ressalvada pelos sujeitos da pesquisa é a habilidade comunicacional que promove a integração entre pessoas e dessas com a organização, interligando-as aos procedimentos dos seus diversos setores, propiciando um conhecimento mútuo sobre a organização, pois, como dizem, o processo de comunicação:

"[...] facilita lidar com todos os funcionários da empresa e ter uma aceitação muito boa desde a diretoria da empresa até o operário do chão de fábrica. Todos precisam ser tratados com a mesma atenção e prioridade".

"Essencial para alcançar todas as gerências que trabalham com informação, para ceder e obter".

"Fundamental para interagir no foco do negócio, que é o resultado".

De fato, a comunicação se caracteriza por ser um processo de disseminação essencial para transmissão do conhecimento gerado pela e para a empresa. Por isso, ratifica-se a afirmação de Silva, J. B. da (2002, p. 35), ao dizer que as organizações necessitam de profissionais que saibam 
[...] potencializar a comunicação, a interpretação de dados, a flexibilidade, a integração funcional e a geração, absorção e a troca de conhecimento, sendo assim capaz de operacionalizar seu conhecimento profissional de modo integrado $[\ldots]$.

Em resumo, além de ser eficiente, ético, de saber trabalhar em equipes e ser bom comunicador, para sete gestores de informação para a indústria esses profissionais devem ser também flexíveis e proativos em suas ações cotidianas e, para oito, a competitividade pessoal é a característica mais importante. Contudo, alguns deles alertaram para o fato de se dar especial atenção à flexibilidade, pois, quando em excesso, pode levar à perda de foco da atuação profissional. Para eles, é preciso ser

"Flexivel a ponto de saber se manter no mercado; estar aberto às mudanças do mercado. Se não somos flexíveis a esse ponto, com certeza vamos perder".

"É preciso ser bastante flexível, mesmo que haja um padrão colocado pela empresa. E preciso saber o melhor momento para se tomar uma atitude diferenciada".

"É necessário tanto [flexibilidade] técnica como comportamental, porque a evolução é muito rápida, havendo, então, necessidade de, o tempo todo, acompanhar as mudanças".

"É muito importante, mas no lado profissional é preciso tomar cuidado para não ficar 'descaracterizado'. É preciso saber onde você realmente trabalha, a área de atuação e alcance do seu trabalho. Muita flexibilidade pode gerar um acúmulo prejudicial de trabalho, sem chegar a um resultado".

Em seu texto, Arruda, Marteleto e Souza (2000, p. 18) escrevem sobre a importância da flexibilização em sentido mais amplo, que vai além exclusivamente da qualificação profissional:

As alterações no perfil profissional não se restringem ao âmbito da qualificação profissional e da gestão do trabalho, mas abrangem o conteúdo e a forma como o trabalho é realizado, como o trabalhador se relaciona e se socializa no ambiente de trabalho. Atingem a subjetividade do sujeito, invadindo seu espaço social, seu comportamento individual e coletivo. Necessita-se de um profissional flexível, apto a atuar em situações de trabalho diferenciadas e a mobilizar seu conhecimento em prol da organização.

Nas justificativas anteriores, percebe-se que a flexibilidade se faz necessária ao acompanhamento das tendências evolutivas do mercado, com o intuito de atendê-las eficazmente. Mesmo que, em toda organização, haja limites de atuação e padrões a serem seguidos, é importantíssimo que se saiba quando e até onde ir, principalmente nos fazeres que dizem respeito à aplicação de técnicas.

A proatividade também figurou como quesito imprescindível ao perfil profissional, estando intimamente ligada à capacidade criativa do gestor de recursos informacionais, uma vez que este precisa estar sempre antenado e pronto para a assimilação de toda e qualquer mudança nos ambientes interno e externo, no sentido de nunca ser cobrado por algo de novo que surgiu no mercado, conforme as declarações a seguir:

"[...] é muito melhor você oferecer uma informação do que ser cobrado por uma que ainda não está disponível. É preciso estar sempre alerta, analisando o que está acontecendo em todos os departamentos da empresa. A mudança é muito grande e se você ficar esperando as coisas acontecerem, com certeza vai ficar pra trás".

"É preciso prever as necessidades do usuário e [estar] à sua frente. Sempre fazendo trabalhos de melhoria, mostrando coisas novas a serem implantadas na empresa, tomando atitude e criando, mas com respaldo superior".

"Aqui é importante estar sempre à frente dos pedidos, vislumbrar as necessidades das gerenciais, é um exemplo".

Essas falas corroboram o que afirmam Tarapanoff, Araújo Júnior e Cormier (2000, p. 94):

Em unidades de informação, a postura competitiva associa-se à proatividade no atendimento às demandas dos usuários, ou seja, está intimamente relacionada à melhor oferta de produtos e serviços, à antecipação, às novas tendências em relação a novas estruturas, à facilidade de acesso à informação, à formação, à agregação de valor e qualidade a esses produtos, bem como à sua personalização (customização), função de redes e de posicionamento no mercado de acordo com as demandas específicas.

Uma vez que cabe ao profissional o gerenciamento das unidades de informação, torna-se inerente a ele a interiorização do espírito proativo. A interpretação da citação anterior não deve restringir-se, exclusivamente, à gestão de ambientes nos quais se buscam informações de forma tradicional (bibliotecas, centros de documentação, arquivos), mas sim a todos, inclusive aqueles que tenham a informação como matéria-prima.

Nesse contexto, os profissionais assinalam a importância da competição no âmbito da empresa, em busca das metas e como forma de relacionamento interpessoal, tendo em vista o aprimoramento dos resultados e dos meios que os levaram a ele, corroborando os resultados de pesquisa divulgada na revista Época, em artigo assinado por Ramos (2005, p. 9), no qual informa que, no Brasil, o individualismo dos profissionais 
cresceu muito, sendo, no entanto, relativamente menor do que nos países anglo-saxônicos. Aqui,

[...] o índice é mais alto nos estados em que a cultura corporativa global se estabeleceu com mais nitidez. São Paulo, como era de prever, é o estado onde os executivos se mostraram mais apegados à palavra 'eu' do que a 'nós'. O contato entre colegas é rarefeito, e o projeto de sobrevivência pessoal na carreira ganha preferência.

Seguindo o exemplo do estado de São Paulo (50 pontos), conforme o ranking de pontos apresentado, os estados do Espírito Santo e Rio de Janeiro (49 pontos) e Minas Gerais (44 pontos) e Paraná (41 pontos) são os mais competitivos.

Para Coutinho e Ferraz (1995, p. 18), essa habilidade é definida como a

[...] capacidade da indústria/empresa em formular e implantar estratégias concorrências, que lhe permitam conservar, de forma duradoura, uma posição sustentável no mercado.

É imprescindível, portanto, que o profissional alie sua competitividade pessoal à institucional, para que haja consonância entre seus objetivos, que se reverterão em resultados para a indústria. Nessa direção, justificam:

"Para permanecer no mercado de trabalho, a competitividade te coloca sempre na posição de aprendiz, na busca de educação continuada e da melhoria contínua".

"A ambição, quando sadia, nos torna mais competitivo, e traz benefícios para empresa que possui esse profissional com essa consciência".

Gilad, citado por Sapiro (1993), no que diz respeito à competitividade como inteligência para aplicação em gestão da informação dentro do tecido organizacional, defende que são observados claramente os seguintes benefícios proporcionados por essa habilidade: identificação de novas oportunidades, idéias compartilhadas, crescente habilidade na antecipação de surpresas, aumento das habilidades gerenciais, integração de vários pontos de vista.

Em suma, registra-se que cada uma das habilidades mencionadas pelos sujeitos do estudo possui, para eles, um grau de importância, porque evidencia virtudes que podem levar os profissionais de todas as áreas do conhecimento a atuar eficazmente, uma vez que

[...] o novo modelo econômico interpõe um novo perfil profissional que requer, além de maior qualificação profissional, maior envolvimento emocional e social do trabalhador. Elege-se como ideal o profissional que potencialize a comunicação, a interpretação de dados, a flexibilização, a integração funcional e a geração, absorção e troca de conhecimento. Este, portanto, deve ser capaz de operacionalizar seu conhecimento profissional de modo integrado às suas aptidões e vivências socioculturais. O trabalhador adestrado, característico do modelo fordista, deixa de atender aos requisitos do novo padrão produtivo. É necessário um profissional capaz de interpretar dados e sinais emitidos pelos novos sistemas autômatos, agindo proativamente a partir desses dados, atuando como agente do processo de inovação (ARRUDA; MARTELETO; SOUZA, 2000, p. 17).

\section{CONSIDERAÇÕES FINAIS}

Para efeito de considerações finais, pode-se inferir que o perfil para se trabalhar como gestor de informação para a indústria está ao alcance de inúmeras áreas de conhecimento, inclusive da biblioteconomia. Mas, para que os postos de trabalho nesse setor se abram aos bibliotecários desejosos de pleitear as vagas que venham a surgir, ou para que mantenham sua empregabilidade com diferencial profissional, é necessário incorporar à sua formação o conhecimento de outras áreas, bem como conhecer o negócio da empresa em que atuam, o que possibilitaria um entendimento maior por parte deles sobre sua atuação. Nessa perspectiva, tendemos a concordar com Tarapanoff (2001, p. 44), quando diz:

O novo modelo prevê objetivos e metodologias compatíveis para todo o ambiente informacional, e exige conhecimento da organização e do negócio, bem como das metodologias e das técnicas de organização e tratamento da informação, aliada a uma visão genérica da tecnologia, de modo a administrar a informação como um recurso econômico e estratégico essencial a eficácia das empresas [...].

Ao se constatar a maior presença de profissionais de outras graduações, fica evidente que o mercado de trabalho ainda está pouco aberto ao bibliotecário, mesmo que, teoricamente, este possua uma formação especializada e dirigida ao processamento, armazenamento, recuperação e disseminação da informação, o que hipoteticamente lhe permitiria atuar em diferenciadas áreas, não o restringindo a um ambiente único. Sendo assim, aqueles que optarem por manter e/ou expandir a sua gama de atuação no segmento de informação para a indústria poderão assumir cargos com denominações profissionais mais abrangentes, como administradores, cientistas ou gestores da informação, desde que não releguem ao segundo plano o aprimoramento de suas capacidades gerenciais e intelectuais e estejam atentos ao novo cenário que indica a necessidade de fazer frente aos novos modelos de gestão executiva em informação para negócios.

Em face dos resultados obtidos neste estudo, reafirma-se que os demais profissionais possuidores de outras formações 
acadêmicas, atuantes neste segmento, constroem sua carreira profissional nessa direção. Ao contrário disso, verifica-se que os participantes da presente pesquisa, possuidores da formação em biblioteconomia, trabalham em indústrias que contam com setores tradicionalmente responsáveis pela gerência, preservação e guarda da documentação produzida e recebida, designados centros de documentação, informação e/ou memória, e voltam-se, prioritariamente, para o processamento técnico, distanciando-se do perfil preconizado por Rezende (2002), que é desejável aos agentes do conhecimento atuantes em indústrias, mas que são oriundos de outras áreas profissionais e não da ciência da informação (arquivologia e biblioteconomia).

Ao socializar esses resultados, pretende-se colocar em discussão os espaços institucionalizados de atuação dos bibliotecários que já não atendem às necessidades informacionais de usuários especializados, por conta da amplitude do valor que a informação assumiu na atualidade, principalmente para as indústrias brasileiras, como foi constatado por este estudo e nos demais realizados no Brasil e referenciados ao longo desta exposição.

Por último, mas não menos relevante, ressalta-se que, para além da certeza da necessidade de novas e inovadoras práticas biblioteconômicas, deve estar a certeza de que o bibliotecário pode vir a ser um agente importante não apenas do crescimento industrial em curso no Espírito Santo, como também pode vir a ser sujeito da própria construção histórica de uma sociedade capixaba, que se pretende que seja mais justa e igualitária.

Artigo submetido em 23/05/2008 e aceito para publicação em 23/05/2008.

\section{REFERÊNCIAS}

ANGELONI, M. T. Elementos intervenientes na tomada de decisão. Ciência da Informação, Brasília, v. 32, n. 1, p. 17-22, jan./ abr. 2003.

ARRUDA, M. C. C.; MARTELETO, R. M.; SOUZA, D. B. de. Educação, trabalho e o delineamento de novos perfis profissionais: o bibliotecário em questão. Ciência da Informação, Brasília, v. 29, n. 3, p. 14-24, set./dez. 2000.

BIANCARDI, A. M. R. et al. O cenário do mercado de trabalho em biblioteconomia na percepção dos empresários capixabas. Páginas AEDD, Lisboa, n. 11, p. 61-67, 2003.

BRAGA, E. M. L. Formação do bibliotecário para o século XXI. 2002. Trabalho de Conclusão de Curso (Graduação em Biblioteconomia). Departamento de Ciências da Informação, Universidade Federal do Espírito Santo, Vitória, 2002.

COUTINHO, L.; FERRAZ, J. C. (Coord.). Estudo da competitividade da indústria brasileira. 3. ed. Campinas: Papirus: Editora da Universidade Estadual de Campinas, 1995.

DAMÁSIO, E.; LONGO, R. M. J. O profissional da informação na indústria: habilidades e competências. Iñ: SEMINÁRIO NACIONAL DE BIBLIOTECAS UNIVERSITÁRIAS, 12., 2002, Recife. Anais eletrônicos... Recife, 2002. Disponível em: < http:// www.ufpe.br/snbu>. Acesso em: 13 maio 2005.

FERREIRA, D. T. Profissional da informação: perfil de habilidades demandadas pelo mercado de trabalho. Ciência da Informação, Brasília, v. 32, n. 1, p. 42-49, jan./abr. 2003.

Findes avalia índices industriais com otimismo. A Gazeta, Vitória, 27 jul. 2005. A Gazeta especial: indústria, p. 2.

GIL, A. C. Como elaborar projetos de pesquisa. 3. ed. São Paulo: Atlas, 1996.

1999.

. Métodos e técnicas de pesquisa social. 5. ed. São Paulo: Atlas,
GUTIERREZ, G. L. Gestão comunicativa: maximizando criatividade e racionalidade. Rio de janeiro : Qualitymark, 1999.

INSTITUTO DE APOIO A PESQUISA E AO DESENVOLVIMENTO JONES DOS SANTOS NEVES. Investimentos previstos para o Espírito Santo 2004-2010. Vitória, 2005.

INSTITUTO EUVALDO LODI. Relatório digital das indústrias no Espírito Santo. Vitória, 2007. Em atualização.

INSTITUTO EUVALDO LODI; INSTITUTO DE DESENVOLVIMENTO INDUSTRIAL DO ESPIRITO SANTO. Guia de negócios: indústrias do Espírito Santo 2002. Vitória, 2002.

MCGEE, J; PRUSAK, L. Gerenciamento estratégico da informação. Rio de Janeiro: Campus, 1994.

MARCHIORI, Patrícia Z. A ciência e a gestão da informação: compatibilidades no espaço profissional. Ciência da Informação, Brasília, v. 31, n. 2, p. 72-79, maio/ago. 2002.

MIRANDA, S. V. Identificando competências informacionais. Ciência da Informação, Brasília, v. 33, n. 2, p. 112-122, maio/ago. 2004.

MONTALLI, K. M. L. Perfil do profissional de informação tecnológica e empresarial. Ciência da Informação, Brasília, v. 26, n. 3, p. 290-295, set./dez. 1997.

PARTICIPAÇÃO setorial das empresas. 150 maiores empresas no Espírito Santo, Vitória, ano 8, n. 8, p. 142-150, 2004.

RAMOS, M. A era da megacompetição. Época Negócios, São Paulo, p. 8-11, 7 mar. 2005. Suplemento da Época, n. 355.

REZENDE, Y. Informação para negócios: os novos agentes do conhecimento e a gestão do capital intelectual. Ciência da Informação, Brasília, v. 31, n. 1, p. 75-83, jan./abr. 2002. 
ROSEMBERG, D. S.; CORREA, L. H. M.; FRAGA, N. E. B. O curso de graduação em ciência da informação da UFES: uma proposta de harmonização curricular entre as áreas de arquivologia e biblioteconomia. Vitória, 2007. Relatório final de pesquisa. Departamento de Ciências da Informação , Universidade Federal do Espírito Santo.

SANTOS, E. N. dos; ROSA, S. Perfil profissional do gerente de recursos informacionais. 2005. Trabalho de Conclusão de Curso (Graduação em Biblioteconomia)- Departamento de Ciências da Informação, Universidade Federal do Espírito Santo, Vitória, 2005.

SAPIRO, Arão. Inteligência empresarial: a revolução informacional da ação competitiva. Revista de Administração de Empresas. São Paulo, v. 33, n. 3, p. 106-124, jul./set. 1993. Disponível em: <http:// www.rae.com.br/redirect.cfm?ID=681 >. Acesso em: 25 jul. 2005.

SCHWARZWALDER, Robert. Librarians as knowledge management agents. EContent. Aug./Sept. 1999. Disponível em: $<$ http://www.findarticles.com> Acesso em: 15 de jun. 2005.

SILVA, A. J. R. P. da; SILVA, E. V. da. Perfil dos gestores da informação para a indústria: um olhar sobre a atuação dos bibliotecários. 2005. Trabalho de Conclusão de Curso (Graduação em Biblioteconomia) Departamento de Ciências da Informação, Universidade Federal do Espírito Santo, Vitória, 2005.
SILVA, J. B. da. O perfil do bibliotecário nas organizações contemporâneas: uma revisão de literatura. 2002. Trabalho de Conclusão de Curso (Graduação em Biblioteconomia) Departamento de Ciências da Informação, Universidade Federal do Espírito Santo, Vitória, 2002.

SILVA, S. L. da. Informação e competitividade: a contextualização da gestão do conhecimento nos processos organizacionais. Ciência da Informação, Brasília, v. 31, n. 2, p. 142-151, maio/ago. 2002.

TARAPANOFF, K. Referencial teórico: introdução. In: TARAPANOFF, K. (Org.). Inteligência organizacional e competitiva. Brasília: EdUnb, 2001. p. 33-49.

; ARAÚJO JÚNIOR, R. H. de; CORMIER, P. M. J. Sociedade da informação e inteligência em unidades de informação. Ciência da Informação, Brasília, v. 29, n. 3, p. 91-100, set./dez. 2000.

TEIXEIRA FILHO, Jayme. Profissionais da informação. Insight Informal, n. 12, ago. 1998. Disponível em: < http://www.informal. com.br/insight/insight12.html>. Acesso em: 21 abr. 2004.

32 ZARIFIAN, Philippe. O modelo da competência: trajetória histórica, desafios atuais e propostas. Tradução Eric R. R. Heneault. São Paulo: Senac, 2003 